\title{
Building Global Citizenship through Network Leadership
}

\author{
Anne Beales \\ NSUN, England \\ Daniel Fisher \\ National Coalition for Mental Health Recovery, USA
}

\section{Introduction}

We are a new generation of service users and consumers who recognise our power and strength: a generation recognising our distress, a generation that is unifying and coming up with new ways to recover from problems that previously seemed unsolvable. Our actual experience of recovery becomes the source of our group's leadership. To nurture the emergence of our leadership, we have had to develop our own structure. We have found that networking is the best way for us to develop our leadership capacity. We formed our group in August 2007 at the IIMHL conference. We named our group Interrelate to emphasise the principles of equality, respect and mutual learning upon which we are founded. The mission statement of Interrelate is:

'To inspire hope and strengthen the capacity of people with mental health issues to lead national and international policy, in order to achieve recovery and wellbeing while protecting human rights.'

\section{Member countries}

We learn new approaches to advocacy by comparing the progress of our member countries towards this mission. These are summarised below.

\section{Australia}

The Australia Mental Health Consumers Network was first funded in 1996 to educate its 2,000 members and conduct conferences. There were some problems with governance and the network lost its funding in 2008. Recently, the new government selected a group of 12 consumer experts to organise a new national user/consumer organisation. Meanwhile, Queensland is getting organised, through the formation of A Way Ahead Queensland. They have the beginnings of a technical assistance center: Our ConsumerPlace.com. A Way Ahead Queensland and the consumer network for the Australian Capitol Territory, ACT, have recently joined Interrelate as associate members.

Challenge: there is an unwillingness by the government to separate the consumer perspective from the carers' perspective.

England

The National Survivor/User Network (NSUN) is three years old and is funded by Comic Relief as well as Tudor Trust and therefore independent of the government. We punch well over our weight, because our goal is putting service user views at the heart of health services. It has been possible, therefore, to work in partnership with providers, commissioners and regulators with varying degrees of success. It is important to network service user-led initiatives such as peer support to maintain our agenda outside the system.

Challenge: there is still too little effective service user influence at the policy-making level and no direct, independent voice of consumers in Parliament. 
Scotland

Voice of eXperience, VOX, started as a peer support group with six people. They have grown and are now working with a variety of user/consumer groups, such as asylum seekers, people who are doubly discriminated against (gay, lesbian, bisexual or transsexual (GLBT), have physical disabilities, are homeless) and HUG (Highland Users Group). They now have a membership of over 1,000 people. They work directly with the Scottish Parliament, various departments and researchers. They receive funding from the government, which has been very supportive of their advocacy.

Challenge: the users have difficulty overcoming tokenism.

Ireland

The Irish Advocacy Network, IAN, trains many users in self-advocacy. IAN has peer advocates in place in most health board areas in Ireland, north and south, who regularly attend acute units and day centres. Sometimes they meet people in the community. Their main job is to give support and information to people with mental health problems by befriending them and offering a confidential listening ear or peer advocacy. Advocates were able to get the concept of recovery and user involvement in policy formation into their Mental Health Commission report of 2004.

Challenge: government does not meaningfully involve users in policy development

Canada

National Network for Mental Health is the user-led network for Canada, founded in 1992 and consisting of over 900 individual members and 126 user-run organisations. They have three staff: a national executive director, a bookkeeper and a national programme director. Their mandate is to advocate, educate and provide expertise and resources for the increased health and well-being of the mental health consumer/survivor community. They enhance cross-disability connecting, by partnering with the Council of Canadians with Disabilities. They are developing standards of practice for peer support.

Challenge: newly formed Mental Health Commission of Canada has not significantly involved consumers

New Zealand

Several years ago, the government distributed funds to 23 local jurisdictions to start user-led groups. Many of these user-run organisations had governance issues; today, Auckland has the only remaining user-run network. 'Recovery' was the unifying principle proposed by the Mental Health Commission. The new National Government is pushing accountability. They are emphasising the need for value for the money spent and partnerships between users and other members of the system. The suicide rate among the Maori is the highest in the world.

Challenge: users have had difficulty sustaining a country-wide group

United States

In 2006 the National Coalition for Mental Health Recovery, NCMHR, was formed from the coming together of 31 state-wide consumer-run organisations, several associate members and two national technical assistance centres. Through this National Coalition and especially by forming a coalition with 12 other groups run by persons with disabilities (Justice for All Action Network), mental health consumers in the US are impacting federal policies. Representatives of NCMHR have met with policy developers in the Obama Administration on several occasions. 
Challenge: carer groups want to restrict consumer freedom and build more hospitals.

Iceland

Hugarafl (which is Icelandic for Mindpower) was formed in 2003 by four recovering users/consumers and an occupational therapist with a lot of experience working within the psychiatric health care system. Hugaraflis leaders have established an educational project - where users visit primary schools, high schools and colleges and related their experiences as well as informing about mental health in general. They have started the peer support project - where users in recovery or recovered meet others who are still in crisis. Hugarafl has also held many conferences, and carried out bed runs as street theatre.

\section{Challenge: it is difficult to get needed financial support}

\section{Why do we feel it is important to have service user leadership?}

We struggle on a day-to-day basis with the issues of mental health problems. We have discovered over and over again that if we meet with non-users before we have our own perspective, before we have our own discussion, before we feel our solidarity, the playing field is not level. In those situations we spend 95\% of our energy trying to get our voice heard. Once we establish our own network leadership, once we are sure about our voice, once we have felt our solidarity, it is possible for us to put our agenda forward in many forums, alongside people whose agenda is different. You cannot have a paralysed voice, because then there is no action.

\section{What do we mean by network leadership?}

Networking is a vital principle of our leadership. Network leadership is a collaborative form of decision-making, which is based on shared power and mutual respect. Hierarchical leadership reminds users of the negative experiences we went through when receiving services. Networks do not superimpose leadership. Networking is based on small groups of users getting together for mutual support. It may seem that service users have more conflicts than non-users, but this is not true. The difference is that conflicts among users are not suppressed. We need, nonetheless, to gain a collective user perspective. We also need to be able to choose our own leaders to represent us. In that fashion, we trust that our leaders will be true to our views.

As leaders we are very loyal to our small support groups. When you have been troubled, isolated, confused and hopeless, you are very loyal to those who help you regain hope and meaning. You cannot sweep aside service user groups that have been helpful. You gain strength, share learning and build capacity by networking among each other in those small groups. Everyone who is a member of a small support group plays a vital role in the development of understanding and growth of everyone else in the group. In this sense, network leadership means that everyone shares in some aspect of leadership. That is why Interrelate advocates for policies that improve the recovery and well-being of everyone via membership in their own network. We realise that we need to learn to negotiate and facilitate relating between members of small groups and the system decision-makers. Managers can help with this process of the emergence of network leadership by taking our groups seriously and not treating our representatives as tokens.

\section{Network leadership enhances citizenship}

We are full citizens and want to be treated as full citizens. Unfortunately, the experience of disempowerment and disconnection produced by being labelled and treated by the mental health system diminishes our sense of citizenship. Through the exercise of network leadership we are able to restore our experience of citizenship. We have found that service user leadership and citizen leadership have many parallels. For instance, service user leaders inspire hope through promoting a vision of recovery and well-being. In a similar fashion, citizen leaders in other fields inspire groups to civic engagement through articulating a shared vision. Service user leaders 
collectively challenge oppressive policies and practices just as citizen leaders challenge oppressive social systems.

\section{An example of network leadership in an Irish hospital}

Our representatives of Interrelate found an example of service user leadership in the Central Mental Hospital in Dublin, Ireland; an example of the will of the human spirit to speak up and advocate on behalf of others whose voice is still small. We heard that the largest number of residents (40\% of 99) were persons found not guilty of crimes by reason of insanity. Their average length of stay is 12 years. Out of this highly locked, very lengthy stay hospital, there was a very impressive resident council. Three residents of the least restrictive unit engaged with our international group of leaders in a thoughtful, attentive fashion. We asked them to share with us their recommendations. They could have personalised their situation and understandably said, 'We want to be discharged'. Instead they made their request in the form of a policy recommendation. They asked us to advocate for conditional discharge, which would enable not only them to be released earlier but other residents as well. Their requests were as follows:

\section{Requests by the Resident's Forum at Central Mental Hospital}

1. Foremost, that the government should develop a policy to enable conditional discharge from Central Mental Hospital to enable the discharge of residents who are ready to live in the community. (We later cautioned the government to word the policy carefully to be flexible and individualised in the application of such a policy, to ensure that it is not universally applied

2. Step down unit for women. (Presently there is only one high security unit at the hospital for women, which means that women are excluded from activities in less secure areas, including much of the work in the garden.)

3. A subsidy for transportation for family members to travel to and from the hospital.

4. Transfer of residents from the least secure unit (\#7) to regional mental hospitals.

5. Enable the residents who produce vegetables in the hospital garden to sell the produce to the hospital, by becoming a qualified supplier. Presently the residents cannot supply their own kitchen with the vegetables they produce because they are not qualified suppliers.

6. Display the client's art on a regular basis in a public exhibition and sell the paintings as has been carried out in Cork.

Through the experience of grave distress in their lives these resident representatives had become leaders because they have learned what worked in their recovery. We were privileged that they had the courage and generosity of spirit to discuss with us what their recommendations were and in turn were interested to hear what was being done in other countries. They are the next generation of leaders and we hope that they can speak at a future IIMHL conference.

\section{Importance of shared values in network leadership}

In traditional leadership styles, authority is exerted by a few over the many by using rules and regulations developed by an elite group of society. In network leadership, the values of hope, respect, inclusion and participation by diverse voices are the sources of authority. Service user leaders have many complicated tasks to accomplish. So it is vital that we affirm our shared values at the outset and continuously thereafter. We have a duty to understand and reform complex systems for the benefit of those that are still in them and to assist in our own healing. We reserve the right to stand outside that system and share what helped and what hurt. We can also work to reform the system from the inside. We can go into the system, which is like a house, and we can turn on its lights. However, we need to realise that it will never be our house. We ultimately need to transform the society through the power of networking. Every person who fights for rights is a night-light. Through participating in a network, we bring all the night-lights together to create a 
beacon of hope for all to see. That beacon then leads us all forward to a liberated society, which unfortunately does not yet exist.

Networks are successful because they are based on diversity. Service users are diverse. We are black, we are white, we are Muslim, we are Christian, we are gay and we are deaf. Service user networks consist of individuals striving to gain citizenship through the goal of selfgovernance. System reform based on a personalisation agenda, individualised budgeting and person-centered planning are steps in the right direction. But, ultimately, the mental health system itself cannot confer full citizenship. One role of our network leadership, then, is to prepare service users to build a mutually supportive, participatory network, where all individuals are recognized as full citizens. If you are connected to loved ones and you are connected to your community, then you are connected to yourself and are a free citizen. Then you will not get lost or confused. You will know who you are and what your purpose in life is. This is the true meaning of social inclusion. Therefore, if our systems worked to strengthen these social connections from the start instead of segregating us there would not be such a need for social inclusion because there would not be social exclusion.

\section{Goals of Interrelate}

1. We need to change public perception and demonstrate that service users are full citizens who are capable of a new form of leadership through networks.

2. We need to change public policies of each of our countries through participation in legislative and regulatory changes based on the human need for well-being and recovery.

3. We need to relate to each other, carers and professionals in a respectful and inclusive fashion.

4. We need to organise, enlarge and strengthen Interrelate and the networks in our countries.

5. We need to enhance our own well-being through staying connected to each other and ourselves so we can be role models to others in distress and those that assist us.

6. We need to demonstrate that our style of network leadership can work not only for us but also for the rest of society, because our recovery depends upon the transformation of all members of society to become global citizens.

\section{Implications for practice:}

- Once we establish our own network leadership, once we are sure about our voice, once we have felt our solidarity, it is possible for us to put our agenda forward in many forums

- Network leadership is a collaborative form of decision-making, which is based on shared power and mutual respect

- One role of our network leadership, then, is to prepare service users to build a mutually supportive, participatory network, where all individuals are recognized as full citizens.

- In network leadership, the values of hope, respect, inclusion and participation by diverse voices are of critical importance

- In network leadership, the values of hope, respect, inclusion and participation by diverse voices are the sources of authority

Acknowledgements

This article is based upon a paper delivered by Anne Beales to the International Initiative for Mental Health Leadership, IIMHL, Conference in Killarney, Ireland, May 2010, and developed by the Interrelate group: Daniel Fisher, US, Shaun McNeil, Scotland, Jenny Speed, Australia, Paddy MacGowan, Ireland, Gary Platz, New Zealand, and Joan Edwards-Karmazyn, Canada. 
Address for correspondence

Anne Beales

National Survivor User Network (NSUN)

27-29 Vauxhall Grove

Vauxhall

London SW8 1SY

England

Email:anne-beales@together-uk.org

Website: www.interrelate.info

Author photos and bios 